\title{
Anticoagulant and Antiplatelet Prescribing Patterns for Patients with Atrial Fibrillation after Percutaneous Coronary Intervention
}

\author{
Erin A Woods, Margaret L Ackman, Michelle M Graham, Sheri L Koshman, Rosaleen M Boswell, \\ and Arden R Barry
}

\begin{abstract}
Background: Current guidelines recommend triple antithrombotic therapy (TAT), defined as acetylsalicylic acid (ASA), clopidogrel, and warfarin, for patients with nonvalvular atrial fibrillation who have undergone percutaneous coronary intervention with stent implantation. The choice of anticoagulant/antiplatelet therapy in this population is ambiguous and complex, and prescribing patterns are not well documented.
\end{abstract}

Objective: To characterize local prescribing patterns for anticoagulant/ antiplatelet therapy after percutaneous coronary intervention in patients with nonvalvular atrial fibrillation.

Methods: A chart review was conducted at a single quaternary cardiology centre. Patients with nonvalvular atrial fibrillation were identified via medical records, and those who underwent percutaneous coronary intervention were identified using a local clinical patient registry. Adult inpatients with nonvalvular atrial fibrillation and a CHADS2 score (based on congestive heart failure, hypertension, age $\geq 75$ years, diabetes mellitus, prior stroke) of 1 or higher who underwent percutaneous coronary intervention from 2011 to 2013 were included. Patients undergoing cardiovascular surgery or transcatheter aortic valve replacement, those with mechanical devices requiring anticoagulation, and those with an allergy to any component of TAT were excluded.

Results: Seventy patients were included. The median age was 75 years, and 52 (74\%) were men. At discharge, 30 (43\%) were receiving TAT and 27 (39\%) were receiving dual antiplatelet therapy (clopidogrel and ASA). No patients received the combination of warfarin and clopidogrel. Among those who received TAT, $90 \%$ (19 of 21) who received a bare metal stent had a recommended duration of 1 month, and $75 \%$ (6 of 8 ) who received a drug-eluting stent had a recommended duration of 1 year. Direct-acting oral anticoagulants with 2 antiplatelet drugs were prescribed for $9 \%$ (6 of 70) of the patients, and 10\% (7 of 70) received ticagrelor and ASA with or without warfarin. Overall, the combination of ASA, oral anticoagulant, and P2Y12 inhibitor was used for 54\% (38/70) of the patients.

Conclusions: Fewer than half of the patients in this study received TAT, and almost $20 \%$ received non-evidence-based therapy with a direct-acting oral anticoagulant or ticagrelor, alone or in combination. Despite current guideline recommendations, the rate of TAT utilization was lower than rates reported in the literature.

Keywords: anticoagulant agents, antiplatelet agents, atrial fibrillation, percutaneous coronary intervention

\section{RÉSUMÉ}

Contexte : Les lignes directrices actuelles recommandent une trithérapie antithrombotique, composée d'acide acétylsalicylique (AAS), de clopidogrel et de warfarine, pour les patients atteints de fibrillation auriculaire non valvulaire qui ont subi l'implantation d'une endoprothèse par intervention coronarienne percutanée. Le choix de traitement par anticoagulant ou antiplaquettaire pour cette population est ambigu et complexe. De plus, les habitudes de prescription ne sont pas bien documentées.

Objectif : Offrir un portrait des habitudes locales de prescription de traitements par anticoagulant ou antiplaquettaire suite à une intervention coronarienne percutanée chez les patients atteints de fibrillation auriculaire non valvulaire.

Méthodes : Une analyse des dossiers médicaux a été menée dans un seul centre quaternaire de cardiologie. Les patients atteints de fibrillation auriculaire non valvulaire ont été identifiés à l'aide de leurs dossiers médicaux. Ceux qui avaient subi une intervention coronarienne percutanée ont été trouvés en consultant un registre local de patients. Les patients adultes hospitalisés qui souffraient d'une fibrillation auriculaire non valvulaire, qui présentaient un score CHADS2 de 1 ou plus (calculé en fonction de la présence d'insuffisance cardiaque congestive, d'hypertension, d'âge égal ou supérieur à 75 ans, de diabète et d'accident vasculaire cérébral antérieur) et qui avaient subi une intervention coronarienne percutanée entre 2011 et 2013 ont été admis. Les patients qui avaient subi une chirurgie cardiovasculaire ou un remplacement valvulaire aortique par cathéter, ceux dotés de prothèses mécaniques nécessitant une anticoagulothérapie et ceux allergiques à un ou plusieurs éléments de la trithérapie antithrombotique ont été exclus.

Résultats : L'âge médian des 70 patients admis était de 75 ans et 52 d'entre eux étaient des hommes. Au moment du congé, 30 (43\%) recevaient une trithérapie antithrombotique et $27(39 \%)$ recevaient une bithérapie antiplaquettaire (AAS et clopidogrel). Aucun patient n'a reçu une association de warfarine et de clopidogrel. Parmi ceux qui ont reçu une trithérapie antithrombotique, la durée recommandée du traitement était d'un mois pour $90 \%$ (19 sur 21) de ceux qui ont reçu une endoprothèse métallique nue et d'un an pour $75 \%$ (6 sur 8 ) de ceux qui ont reçu une endoprothèse à élution de médicaments. On a prescrit pour $9 \%$ (6 sur 70) des patients un anticoagulant oral direct accompagné de deux antiplaquettaires. De plus, $10 \%$ (7 sur 70) des patients ont reçu du ticagrelor et de l'AAS avec ou sans warfarine. Dans l'ensemble, la combinaison d'AAS, d'un anticoagulant oral et d'un inhibiteur du P2Y12 a été employée chez 54 \% (38 sur 70) des patients. 


\section{Can J Hosp Pharm. 2016;69(4):280-85}

Conclusions : Moins de la moitié des patients de la présente étude ont reçu une trithérapie antithrombotique et près de $20 \%$ ont reçu un traitement non fondé sur des données probantes composé d'un anticoagulant oral direct ou de ticagrelor, employés seuls ou en association. Malgré les recommandations des lignes directrices actuelles, le taux de recours à la trithérapie antithrombotique était plus faible que les pourcentages présentés dans la littérature.

Mots clés : anticoagulants, antiplaquettaires, fibrillation auriculaire, intervention coronarienne percutanée

\section{INTRODUCTION}

$\mathrm{I}_{\mathrm{in}}^{\mathrm{n}}$ $n$ the setting of percutaneous coronary intervention with stent implantation, the standard of care is dual antiplatelet therapy with acetylsalicylic acid (ASA) and a P2Y12 inhibitor, such as clopidogrel or ticagrelor. ${ }^{1}$ Comorbidities such as atrial fibrillation may influence decisions about antiplatelet therapy for patients who have undergone percutaneous coronary intervention. ${ }^{2}$ Given the substantial risk of cardioembolic stroke in patients with atrial fibrillation, long-term thromboprophylaxis with an oral anticoagulant is recommended for most patients. ${ }^{3-5}$ It is estimated that $5 \%$ to $10 \%$ of patients who undergo percutaneous coronary intervention also have an indication for an oral anticoagulant, such as atrial fibrillation. ${ }^{6-8}$ The combination of dual antiplatelet therapy with oral anticoagulant is commonly referred to as triple antithrombotic therapy (TAT). Current recommendations for TAT are based on evidence for preventing both stent thrombosis after percutaneous coronary intervention and cardioembolic stroke in atrial fibrillation. Consensus documents advise that in this population, all patients should receive TAT for at least 1 month and up to 12 months, depending on the bleeding risk and type of stent used. ${ }^{2,4}$

There is a lack of high-quality evidence in the literature regarding the optimal oral anticoagulant and antiplatelet regimen for patients with atrial fibrillation after percutaneous coronary intervention. Most guidelines, including the Canadian Cardiovascular Society guidelines for atrial fibrillation, ${ }^{5}$ suggest that, if indicated, TAT should be considered for patients with a CHADS2 score (based on congestive heart failure, hypertension, age $\geq 75$ years, diabetes mellitus, prior stroke) of 2 or higher; however, this recommendation is based primarily on retrospective trials, consensus opinion, and standard of care. All of the guidelines $^{3-5}$ also suggest that the use of TAT be based on a balanced assessment of each patient's risk of stroke and bleeding, and that the duration of TAT be minimized to reduce the risk of bleeding. The guidelines give no specific recommendations about initiating TAT in patients who have had recent bleeding events, other than that patients should have an assessment of overall bleeding risk with tools such as the HASBLED score (based on hypertension, abnormal renal and liver function, stroke, bleeding, labile international normalized ratio, elderly, drugs or alcohol). ${ }^{3-5}$ Recently published randomized controlled trials have provided evidence to support alternatives to TAT, but those studies were limited by methodological quality. ${ }^{9,10}$ The WOEST trial (What is the Optimal Antiplatelet and Anticoagulant Therapy in Patients with Oral Anticoagulation and Coronary Stenting trial) concluded that, relative to TAT, warfarin and clopidogrel reduced bleeding without increasing cardiovascular events. However, the impact of this single study on current practice is unknown.

Prescribing patterns for this patient population are not well characterized. The objective of the current study was to characterize local practice patterns relating to anticoagulant and antiplatelet therapy in patients with nonvalvular atrial fibrillation after percutaneous coronary intervention. In addition, patterns of anticoagulant and antiplatelet utilization before and after the online publication of the WOEST trial on February 13, 2013, were examined.

\section{METHODS}

A review of medical charts was performed at a single quaternary cardiology centre. Adult patients (age $\geq 18$ years) who had a history of nonvalvular atrial fibrillation as an indication for chronic anticoagulation (CHADS2 score $\geq 1$ ) and who underwent inpatient percutaneous coronary intervention from January 1, 2011, to December 31, 2013, were included. Nonvalvular atrial fibrillation was defined as atrial fibrillation not related to rheumatic valvular disease or mechanical heart valves. For the purposes of this study, TAT was defined as combination therapy with warfarin, clopidogrel, and ASA, because efficacy and safety data are not currently available for other combinations involving newer anticoagulant agents (i.e., direct-acting oral anticoagulants) and P2Y12 inhibitors (e.g., prasugrel, ticagrelor). The exclusion criteria were cardiovascular surgery during the index hospital admission, mechanical devices requiring anticoagulation, transcatheter aortic valve replacement, or documented allergy to any component of TAT.

Patients with nonvalvular atrial fibrillation were identified through the institutional medical records using the International Statistical Classification of Diseases and Related Health Problems (ICD-10) code I48 (including all subtypes). Patients who underwent percutaneous coronary intervention were identified from a longitudinal clinical registry that collects information on all local patients undergoing cardiac catheterization. ${ }^{11}$ The cohort 
from medical records was cross-referenced with the clinical patient registry to identify patients with both nonvalvular atrial fibrillation and percutaneous coronary intervention during the index admission. A single investigator (E.A.W.) performed the medical chart review using a standardized data collection form. Data collected included patient demographic characteristics, comorbidities, and discharge antiplatelet and anticoagulant medications. The Health Research Ethics Office at the University of Alberta approved this study.

\section{RESULTS}

A total of 109 patients were identified, and 70 were included in the review. The most common reasons for exclusion were lack of stent insertion (15 patients), death during the index admission (9), and cardiovascular surgery during the index admission (9). Baseline characteristics are summarized in Table 1. The median age was 75 years, and 52 (74\%) were male. The majority of patients had hypertension (51 [73\%]) and dyslipidemia (49 [70\%]). The most common indication for coronary angiography was an acute coronary syndrome (59 [84\%]), with most patients receiving a bare metal stent $(46[66 \%])$. The median CHADS2 and HASBLED scores were 2 and 3, respectively. ${ }^{4}$

The most common regimen at discharge was TAT, which was prescribed for $30(43 \%)$ of the 70 patients, followed by dual antiplatelet therapy with clopidogrel and ASA (27 [39\%]) (Table 2). None of the patients received the WOEST regimen of warfarin and clopidogrel. The remaining patients received various combinations of other antiplatelet and anticoagulant agents. A combination of 2 antiplatelet agents with a directacting oral anticoagulant was prescribed for $6(9 \%)$ of the 70 patients, and $5(7 \%)$ received ticagrelor and ASA. Of the entire cohort, 38 patients $(54 \%)$ received a combination of an oral anticoagulant and 2 antiplatelet agents, including a direct-acting oral anticoagulant and/or ticagrelor. None of the nine patients (13\%) with previous gastrointestinal bleeding were prescribed TAT on discharge. Of the 30 patients who received TAT, 13 (43\%) had a CHADS2 score of 1 , and $17(57 \%)$ had a CHADS2 score of 2 or greater. In addition, only $1(3 \%)$ of these 30 patients had a HASBLED score of 1 , whereas $12(40 \%)$ had a HASBLED score of 2, and 17 (57\%) had a HASBLED score of 3 or higher.

For most of the patients who received a drug-eluting stent, 1 year of TAT was prescribed, whereas 1 month of TAT was prescribed for most of those who received a bare metal stent (Table 3).

\section{DISCUSSION}

In the current study, fewer than half of patients at the study site received TAT at discharge. This rate is much lower than those reported in other recently published observational studies, which ranged from $64 \%$ to $72 \% .{ }^{12,13}$ Schlitt and others ${ }^{12}$ reported that
Table 1. Baseline Characteristics of Patients with Atrial Fibrillation after Percutaneous Coronary Intervention

\begin{tabular}{|c|c|c|}
\hline \multirow{2}{*}{$\begin{array}{l}\text { Characteristic } \\
\text { Sex, male }\end{array}$} & \multicolumn{2}{|c|}{$\begin{array}{l}\text { No. (\%) of Patients } \\
\quad(n=70)\end{array}$} \\
\hline & 52 & $(74)$ \\
\hline \multicolumn{3}{|l|}{ Medical conditions* } \\
\hline Hypertension & 51 & (73) \\
\hline Dyslipidemia & 49 & (70) \\
\hline Heart failure & 20 & (29) \\
\hline Diabetes mellitus & 15 & $(21)$ \\
\hline Previous myocardial infarction & 15 & $(21)$ \\
\hline Chronic obstructive pulmonary disease & 13 & (19) \\
\hline Cerebrovascular accident & 11 & (16) \\
\hline Anemia & 11 & (16) \\
\hline Gastroesophageal reflux disease & 10 & (14) \\
\hline Current smoker & 10 & (14) \\
\hline Previous gastrointestinal bleeding & 9 & (13) \\
\hline Current alcohol abuse & 4 & (6) \\
\hline End-stage renal disease & 3 & (4) \\
\hline Pulmonary embolism & 1 & (1) \\
\hline \multicolumn{3}{|l|}{ Indication for angiography } \\
\hline Acute coronary syndrome & 59 & (84) \\
\hline Stable angina & 4 & (6) \\
\hline Other & 7 & $(10)$ \\
\hline \multicolumn{3}{|l|}{ Stent type } \\
\hline Bare metal & 46 & $(66)$ \\
\hline Drug-eluting & 24 & (34) \\
\hline \multicolumn{3}{|l|}{ No. of stents } \\
\hline 1 & 44 & (63) \\
\hline 2 & 21 & (30) \\
\hline 3 & 4 & (6) \\
\hline 4 & 1 & (1) \\
\hline \multicolumn{3}{|l|}{ Stent location } \\
\hline Left anterior descending artery & 22 & (31) \\
\hline Right coronary artery & 17 & (24) \\
\hline Left circumflex artery & 7 & (10) \\
\hline Other & 24 & (34) \\
\hline \multicolumn{3}{|l|}{ CHADS2 score } \\
\hline 1 & 28 & $(40)$ \\
\hline 2 & 24 & (34) \\
\hline 3 & 9 & (13) \\
\hline 4 & 6 & (9) \\
\hline 5 & 3 & (4) \\
\hline \multicolumn{3}{|l|}{ HASBLED score } \\
\hline 1 & 7 & $(10)$ \\
\hline 2 & 20 & (29) \\
\hline 3 & 26 & (37) \\
\hline 4 & 16 & (23) \\
\hline 5 & 1 & (1) \\
\hline \multicolumn{3}{|c|}{$\begin{array}{l}\text { CHADS2 = congestive heart failure, hypertension, age } \geq 75 \\
\text { years, diabetes mellitus, prior stroke; HASBLED = hypertension, } \\
\text { abnormal renal and liver function, stroke, bleeding, labile } \\
\text { international normalized ratio, elderly, drugs or alcohol. } \\
\text { *Some patients had more than one condition. }\end{array}$} \\
\hline
\end{tabular}

the most common antithrombotic regimen on discharge among 963 patients with atrial fibrillation who underwent percutaneous coronary intervention was TAT (71.8\%), containing warfarin (60.9\% of all patients) or low-molecular-weight heparin 
Table 2. Anticoagulant and Antiplatelet Regimens at Discharge

\begin{tabular}{lcc} 
Regimen & $\begin{array}{c}\text { No. (\%) of Patients } \\
(\boldsymbol{n}=\mathbf{7 0})\end{array}$ \\
\hline $\begin{array}{l}\text { ASA, clopidogrel, and warfarin } \\
\text { (triple antithrombotic therapy) }\end{array}$ & 30 & $(43)$ \\
$\begin{array}{l}\text { ASA and clopidogrel } \\
\text { (dual antiplatelet therapy) }\end{array}$ & 27 & $(39)$ \\
ASA and ticagrelor & 5 & $(7)$ \\
$\begin{array}{l}\text { ASA, clopidogrel, and a direct-acting } \\
\text { Oral anticoagulant }\end{array}$ & 4 & $(6)$ \\
ASA, ticagrelor, and warfarin & & \\
ASA, ticagrelor, and a direct-acting & 2 & $(3)$ \\
Oral anticoagulant & 2 & $(3)$ \\
ASA = acetylsalicylic acid. & &
\end{tabular}

$(10.9 \%){ }^{12}$ The next most common regimens were dual antiplatelet therapy $(17.2 \%)$ and an oral anticoagulant with 1 antiplatelet agent (10.0\%). Ho and others ${ }^{13}$ examined stroke and bleeding rates among 602 patients with atrial fibrillation who underwent percutaneous coronary intervention and for whom TAT or dual antiplatelet therapy was prescribed. TAT was the predominant strategy, used for $63.5 \%$ of the patients. Interestingly, the second most common regimen was dual antiplatelet therapy. Despite evidence showing a reduction in stroke risk for patients with atrial fibrillation relative to ASA alone, dual antiplatelet therapy was inferior to warfarin with a similar risk of bleeding. ${ }^{14,15}$

Several factors may account for the low observed utilization of TAT in the current study. First, the overall risk of stroke in this cohort was low. About $60 \%$ of patients had a CHADS2 score of 2 or greater, as opposed to about $70 \%$ of patients in recent observational studies. ${ }^{12,13}$ As well, the median HASBLED score was 3, which indicates a relatively high risk of bleeding; however, the HASBLED score has not been validated for patients receiving TAT. Because the HASBLED score was designed to evaluate bleeding risk for patients with atrial fibrillation who are receiving oral anticoagulant only, it is unknown whether it can accurately assess the true risk of bleeding with TAT. Of the patients with a CHADS2 score of 3 or higher, TAT was prescribed for half. Second, a history of gastrointestinal bleeding is an important consideration when determining the appropriateness of TAT. A recent observational study found that patients receiving TAT had a significantly higher rate of gastrointestinal bleeding than patients receiving dual antiplatelet therapy, with a similar rate of major bleeding. ${ }^{13}$ In the current study, no patients with previous gastrointestinal bleeding were given TAT on discharge. It could be hypothesized that this was due to the risk of recurrent bleeding; however, the reasons for drug selection were not collected. Previous gastrointestinal bleeding is not an absolute contraindication to TAT; however, it is an important factor to consider when initiating this regimen. Given the increased rate of gastrointestinal bleeding with TAT, it would be reasonable for clinicians to select dual antiplatelet therapy for patients with a history of gastrointestinal bleeding. ${ }^{13}$ In addition, the rate of bare metal stent use in the current study (66\%) was higher than expected. Of the 9 patients with previous gastrointestinal bleeding, 4 (44\%) received a bare metal stent and 5 (56\%) received a drug-eluting stent. In a recent observational study, the rate of use of bare metal stents was only $57 \% .{ }^{12}$ The choice of a bare metal stent over a drug-eluting stent may have been a conscious decision by the cardiac interventionalist to reduce the duration of TAT. Because the daily stroke risk for patients with nonvalvular atrial fibrillation is low, the interventionalist may have taken a calculated risk to hold the oral anticoagulant in favour of dual antiplatelet therapy for 1 month in patients with a bare metal stent to minimize potential bleeding. However, bare metal stents are no longer standard of practice because of an increased risk of in-stent restenosis. Therefore, the short-term benefit of reduced bleeding may be offset by the long-term risk of in-stent restenosis.

The WOEST trial, which examined clopidogrel with or without ASA in patients who were taking an oral anticoagulant and who underwent percutaneous coronary intervention, showed that the combination of warfarin and clopidogrel significantly reduced any bleeding at 1 year. ${ }^{9}$ Although underpowered for this end point, the use of warfarin and clopidogrel without ASA did not increase the risk of thrombotic events relative to TAT. However, the limitations of the WOEST study included a relatively small sample size, and the primary outcome was driven predominantly by minor bleeding. Interestingly, no patients in the current study were taking the combination of warfarin and clopidogrel at discharge. Although the WOEST trial was published partway through the period of the current study, the WOEST data do not appear to have substantially affected prescribing patterns at the study site. The more recently published ISAR-TRIPLE trial (Intracoronary Stenting and Antithrombotic Regimen-Testing of a 6-Week versus a 6-Month Clopidogrel Treatment Regimen in Patients with Concomitant Aspirin and Oral Anticoagulant Therapy Following Drug-Eluting Stenting) examined a variable duration of

\section{Table 3. Prescribed Duration of Triple Antithrombotic Therapy According to Stent Type}

\begin{tabular}{|c|c|c|c|}
\hline \multirow[b]{2}{*}{ Type of Stent } & \multicolumn{3}{|c|}{ Prescribed Duration; No. (\%) of Patients } \\
\hline & 1 month & 3 months & 12 months \\
\hline Bare metal $(n=21)$ & 19 (90) & (5) & (5) \\
\hline Drug-eluting $(n=8)^{*}$ & $1 \quad(12)$ & 1 (12) & $6(75)$ \\
\hline
\end{tabular}

*Data missing for one patient. 
clopidogrel therapy (6 weeks versus 6 months) as a component of TAT in patients with atrial fibrillation who underwent percutaneous coronary intervention with implantation of a drugeluting stent. ${ }^{10}$ That study found no statistically significant difference between groups with regard to a net clinical outcome that included major bleeding and ischemic events. Because the ISAR-TRIPLE trial was published after the study period for the current trial, it remains to be seen how its results will affect practice at the study institution.

There are limited data to support the efficacy and safety of direct-acting oral anticoagulants and newer P2Y12 inhibitors in patients with atrial fibrillation after percutaneous coronary intervention. Patients needing long-term oral anticoagulant therapy were excluded from the landmark trials of prasugrel and ticagrelor. ${ }^{16,17}$ Despite this absence of data, non-evidence-based combinations that contained a direct-acting oral anticoagulant and/or ticagrelor were used in about $20 \%$ of patients in the current study. Ticagrelor, rivaroxaban, and dabigatran were not on the hospital formulary and were not covered under the provincial drug plan until midway through the study period, whereas apixaban was not on formulary or on the provincial drug plan until after the study period; formulary and drug plan status may have affected utilization of these agents. Trials investigating the use of direct-acting oral anticoagulants in combination with 2 antiplatelet agents in patients with acute coronary syndrome (as opposed to atrial fibrillation) have shown conflicting results. A trial investigating apixaban in addition to dual antiplatelet therapy in acute coronary syndrome was terminated early because of a high rate of major bleeding in the treatment group. ${ }^{18} \mathrm{~A}$ second trial examining low-dose rivaroxaban plus dual antiplatelet therapy after acute coronary syndrome found an increase in major bleeding, but also a reduction in cardiovascular events and all-cause mortality. ${ }^{19} \mathrm{~W}$ ith respect to the newer P2Y12 inhibitors, ticagrelor has never been studied in combination with an oral anticoagulant, and prasugrel combined with warfarin and ASA has been shown to significantly increase bleeding relative to TAT with clopidogrel. ${ }^{6}$ The PIONEER AF-PCI trial (Study Exploring Two Strategies of Rivaroxaban and One of Oral Vitamin K Antagonist in Patients with Atrial Fibrillation Who Undergo Percutaneous Coronary Intervention), an ongoing randomized controlled trial comparing rivaroxaban plus dual antiplatelet therapy or a P2Y12 inhibitor in patients with atrial fibrillation after percutaneous coronary intervention, will provide valuable insight into this challenging therapeutic dilemma. ${ }^{20}$

The primary limitation of the current study was its retrospective design, which did not allow for adjustment of known and unknown biases and confounders and which relied on the accuracy of documentation in the patients' charts. To counteract this limitation, a single investigator collected and entered all data using prespecified definitions. As well, clinical outcome data, such as rates of adverse cardiovascular or bleeding events, were not collected.

\section{CONCLUSION}

Fewer than half of the patients in the study cohort received TAT, a rate lower than previously reported in the literature. Interestingly, this result was not due to the utilization of warfarin and clopidogrel, a 2-drug combination studied in the WOEST trial, which was published during our data collection period. The second most common regimen, at almost $40 \%$, was dual antiplatelet therapy, and about one-fifth of patients received non-evidence-based combinations involving a direct-acting oral anticoagulant and/or ticagrelor. The low rate of TAT and the relatively high use of non-evidence-based regimens in this study should prompt an examination of current practice patterns to ensure that treatment is safe and effective for each patient. The variety of regimens observed highlights the importance of an individualized assessment of the benefits and risks of TAT in patients with atrial fibrillation who undergo percutaneous coronary intervention; it also highlights the need for more data regarding the efficacy and safety of regimens containing a directacting oral anticoagulant and/or a newer P2Y12 inhibitor.

\section{References}

1. Levine GN, Bates ER, Blankenship JC, Bailey SR, Bittl JA, Cercek B, et al. $2011 \mathrm{ACCF} / \mathrm{AHA} / \mathrm{SCAI}$ guideline for percutaneous coronary intervention: a report of the American College of Cardiology Foundation/American Heart Association Task Force on practice guidelines and the Society for Cardiovascular Angiography and Interventions. Circulation. 2011;124(23):e574-651.

2. Barry AR, Ackman ML. Triple antithrombotic therapy in patients with atrial fibrillation who have undergone percutaneous coronary intervention with stent implantation. Am J Health Syst Pharm. 2012;69(17):1485-93.

3. January CT, Wann LS, Alpert JS, Calkins H, Cigarroa JE, Cleveland JC, et al. $2014 \mathrm{AHA} / \mathrm{ACC} / \mathrm{HRS}$ guideline for the management of patients with atrial fibrillation: a report of the American College of Cardiology/American Heart Association Task Force on practice guidelines and the Heart Rhythm Society. Circulation. 2014;130(23):e199-267. Erratum in: Circulation. 2014;130(23):e272-4.

4. Camm AJ, Lip GY, De Caterina R, Savelieva I, Atar D, Hohnloser SH, et al.; ESC Committee for Practice Guidelines. 2012 focused update of the ESC guidelines for the management of atrial fibrillation: an update of the 2010 ESC guidelines for the management of atrial fibrillation. Developed with the special contribution of the European Heart Rhythm Association. Eur Heart J. 2012;33(21):2719-47.

5. Skanes AC, Healey JS, Cairns JA, Dorian P, Gillis AM, McMurtry MS, et al. Focused 2012 update of the Canadian Cardiovascular Society atrial fibrillation guidelines: recommendations for stroke prevention and rate/rhythm control. Can J Cardiol. 2012;28(2):125-36.

6. Sarafoff N, Martischnig A, Wealer J, Mayer K, Mehilli J, Sibbing D, et al. Triple therapy with aspirin, prasugrel, and vitamin $\mathrm{K}$ antagonists in patients with drug-eluting stent implantation and an indication for oral anticoagulation. J Am Coll Cardiol. 2013;61(20):2060-6.

7. Gao F, Zhou YJ, Wang ZJ, Yang SW, Nie B, Liu XL, et al. Meta-analysis of the combination of warfarin and dual antiplatelet therapy after coronary stenting in patients with indications for chronic oral anticoagulation. Int J Cardiol. 2011;148(1):96-101.

8. Zhao HJ, Zheng ZT, Wang ZH, Li SH, Zhang Y, Zhong M, et al. "Triple therapy" rather than "triple threat": a meta-analysis of the two antithrombotic regimens after stent implantation in patients receiving long-term oral anticoagulant treatment. Chest. 2011;139(2):260-70.

9. Dewilde WJ, Oirbans T, Verheugt FW, Kelder JC, De Smet BJ, Herrman JP, et al. Use of clopidogrel with or without aspirin in patients taking oral anticoagulant therapy and undergoing percutaneous coronary intervention: an open-label, randomised, controlled trial. Lancet. 2013;381(9872):1107-15. 
10. Fiedler KA, Maeng M, Mehilli J, Schulz-Schüpke S, Byrne BA, Sibbing D, et al. Duration of triple therapy in patients requiring oral anticoagulation after drug-eluting stent implantation: the ISAR-TRIPLE trial. J Am Coll Cardiol. 2015;65(16):1619-29.

11. Ghali WA, Knudtson ML. Overview of the Alberta Provincial Project for Outcome Assessment in Coronary Heart Disease. On behalf of the APPROACH investigators. Can J Cardiol. 2000;16(10):1225-30.

12. Schlitt A, Rubboli A, Lip GH, Lahtela H, Valencia J, Karjalainen PP, et al. The management of patients with atrial fibrillation undergoing percutaneous coronary intervention with stent implantation: in-hospital-data from the Atrial Fibrillation undergoing Coronary Artery Stenting study. Catheter Cardiovasc Interv. 2013;82(7):E864-70.

13. Ho KW, Ivanov J, Freixa X, Overgaard CB, Osten MD, Ing D, et al. Antithrombotic therapy after coronary stenting in patients with nonvalvular atrial fibrillation. Can J Cardiol. 2013;29(2):213-8.

14. ACTIVE Investigators, Connolly SJ, Poque J, Hart RG, Hohnloser SH, Pfeffer M, et al. Effect of clopidogrel added to aspirin in patients with atrial fibrillation. N Engl J Med. 2009;360(20):2066-78.

15. ACTIVE Writing Group on behalf of the ACTIVE Investigators, Connolly S, Pogue J, Hart R, Pfeffer M, Hohnloser S, et al. Clopidogrel plus aspirin versus oral anticoagulation for atrial fibrillation in the Atrial fibrillation Clopidogrel Trial with Irbesartan for prevention of Vascular Events (ACTIVE W): a randomised controlled trial. Lancet. 2006;367(9526):1903-12.

16. Wiviott SD, Braunwald E, McCabe CH, Montalescot G, Ruzyllo W, Gottlieb S, et al. Prasugrel versus clopidogrel in patients with acute coronary syndromes. N Engl J Med. 2007;357(20):2001-15.

17. Wallentin L, Becker RC, Budaj A, Cannon CP, Emanuelsson H, Held C, et al. Ticagrelor versus clopidogrel in patients with acute coronary syndromes. N Engl J Med. 2009;361(11):1045-57.

18. Alexander JH, Lopes RD, James S, Kilaru R, He Y, Mohan P, et al. Apixaban with antiplatelet therapy after acute coronary syndrome. $N$ Engl J Med. 2011;365(8):699-708

19. Mega JL, Braunwald E, Wiviott SD, Bassand JP, Bhatt DL, Bode C, et al. Rivaroxaban in patients with a recent acute coronary syndrome. $N$ Engl J Med. 2012;366(1):9-19.

20. Janssen Scientific Affairs, LLC. A study exploring two strategies of rivaroxaban (JNJ39039039; BAY-59-7939) and one of oral vitamin K antagonist in patients with atrial fibrillation who undergo percutaneous coronary intervention (PIONEER AF-PCI). In: ClinicalTrials.gov [database]. Bethesda (MD): US National Institutes of Health; 2015 [cited 2015 Nov 25]. Available from: http://clinicaltrials.gov/ct2/show/NCT01830543
Erin A Woods, BSP, ACPR, is with Pharmacy Services, University of Alberta Hospital/Mazankowski Alberta Heart Institute, Alberta Health Services, Edmonton, Alberta.

Margaret L Ackman, BSC(Pharm), PharmD, ACPR, FCSHP, is with Pharmacy Services, University of Alberta Hospital/Mazankowski Alberta Heart Institute, Alberta Health Services, Edmonton, Alberta.

Michelle M Graham, MD, FRCPC, is with the Division of Cardiology, Faculty of Medicine and Dentistry, University of Alberta, Edmonton, Alberta.

Sheri L Koshman, BSCPharm, PharmD, ACPR, is with the Division of Cardiology, Faculty of Medicine and Dentistry, University of Alberta, Edmonton, Alberta.

Rosaleen M Boswell, BSCPharm, ACPR, is with Pharmacy Services, University of Alberta Hospital/Mazankowski Alberta Heart Institute, Alberta Health Services, Edmonton, Alberta.

Arden R Barry, BSC, BSC(Pharm), PharmD, ACPR, is with the Faculty of Pharmaceutical Sciences, University of British Columbia, Vancouver, British Columbia.

Competing interests: None declared.

\section{Address correspondence to:}

Erin A Woods

Pharmacy

University of Alberta Hospital

Walter Mackenzie Centre 0G1.01

8440 - 112 Street NW

Edmonton $\mathrm{AB}$ T6G 2B7

e-mail: Erin.Woods@albertahealthservices.ca

Funding: None received.

Acknowledgements: The authors would like to thank Colleen Norris, $\mathrm{PhD}$, and Danielle Southern, MSc, of the APPROACH team for their assistance with data retrieval.

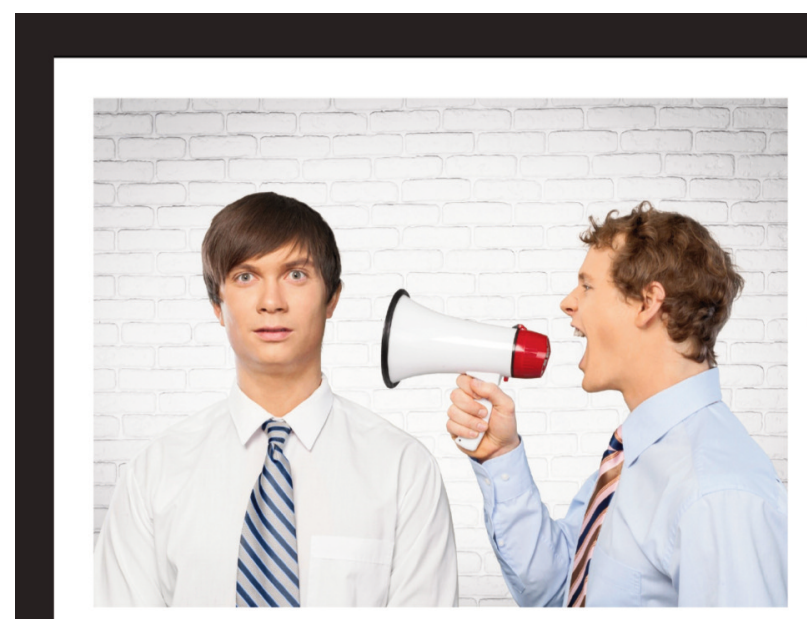

id you know that most of our new members and supporters learn about CSHP through word of mouth?

Over the years, you have referred hundreds of your friends and colleagues to the Society-THANK YOU!

We'd like to encourage you to keep talking about us!

CSHP offers a referral program that allows you to gain credit that can be applied to publications, continuing education programs, and membership

* Receive a $\mathbf{\$ 1 0}$ credit for referring other members and supporters.

* Receive a $\mathbf{\$ 5}$ credit for referring other students and residents.

New members and supporters will have the opportunity to list you as the person who referred them to CSHP on their application-it's that simple!

For more information, please contact:

Membership Services 